\title{
Probiotic treatments for induction and maintenance of remission in inflammatory bowel diseases: a meta-analysis of randomized controlled trials
}

\author{
Mikihiro Fujiya $\cdot$ Nobuhiro Ueno $\cdot$ Yutaka Kohgo
}

Received: 5 November 2013/Accepted: 12 November 2013/Published online: 28 December 2013

(C) Springer Japan 2013

\begin{abstract}
Probiotics have been used for the treatment of inflammatory bowel diseases (IBD). However, the effects of probiotics on the induction and maintenance of remission in ulcerative colitis (UC) or Crohn's disease (CD) still remain controversial. This systematic review verified the findings of high-quality randomized controlled trials (RCTs) which investigated the therapeutic effects of probiotics on IBD. After the quality assessment, 20 RCTs which investigated the effects of probiotics on the induction or maintenance of remission in IBD were identified. From the results of the validation of these RCTs, beneficial effects of probiotic treatments to improve the response rate and remission rate on the remission induction therapies [risk ratio (RR) $1.81 ; 95 \%$ confidence interval (CI) 1.40-2.35 and RR 1.56; $95 \%$ CI 0.95-2.56, respectively] were verified. Furthermore, probiotic treatments exhibited effects equal to mesalazine on the maintenance of remission in UC (RR 1.00; $95 \%$ CI 0.79-1.26). In contrast, no significant effect of probiotic treatments was shown in either the induction or maintenance of remission in $\mathrm{CD}$. Because there were many variations in the conditions among these studies, a further analysis evaluating the effects of probiotic treatments in IBD is needed to clarify the optimal probiotics and treatment regimens for each condition or population in IBD patients.
\end{abstract}

Keywords Probiotics - Inflammatory bowel disease . Ulcerative colitis · Crohn's disease · Lactobacillus . Bifidobacterium $\cdot$ Escherichia coli $\cdot$ Ileal pouch

M. Fujiya $(\bowtie) \cdot$ N. Ueno $~ Y$ Y. Kohgo

Division of Gastroenterology and Hematology/Oncology, Department of Medicine, Asahikawa Medical University, 2-1 Midorigaoka-higashi, Asahikawa, Hokkaido 078-8510, Japan e-mail: fjym@asahikawa-med.ac.jp

\section{Introduction}

Inflammatory bowel disease (IBD) is a chronic and refractory intestinal inflammation which mainly comprises ulcerative colitis and Crohn's disease, and whose causes are still unclear. The pathogenesis of IBD is thought to be associated with genetic susceptibility, an impairment of intestinal epithelial cells and host immune dysfunctions, as well as an imbalance of commensal bacteria[1, 2], because the mammalian intestine possesses more than 2,000 species of bacterial organisms that are indispensable partners for developing intestinal tissue and maintaining its homeostasis [3-5].

Probiotics, which are defined as "live microorganisms which confer a health benefit on the host, when administered in adequate amounts" [6], have potential effects on human health, as well as the treatment of intestinal disorders such as IBD. Indeed, the beneficial effects of probiotics were proposed more than 100 years ago [7, 8]. Recent advances in this field have proposed several mechanisms by which probiotics may improve intestinal disorders, including inhibiting the growth of pathogenic bacteria [917], enhancing the intestinal barrier function [18-24] and modulating the host immune responses [25-40]. Based on the results of etiological and pre-clinical studies of the effects of probiotics, many clinical trials have been conducted, and have suggested that probiotics are potentially useful in the treatment in IBD patients. However, the data from these studies were based on various subjects using different genera, species, strains and doses of probiotics [41, 42]. The sample sizes of these studies have been relatively small, so there has been no definitive evidence. The present review systematically evaluates the effects of probiotic treatments on IBD based on existing randomized controlled trials (RCTs). 


\section{Methods}

Retrieval strategy and quality assessment

A meta-analysis was conducted to evaluate the effects of probiotic treatment on IBD. The data from PubMed (1997 to August 2013) and the Cochrane Controlled Trials Register (1997 to August 2013) were searched. The keywords used were: probiotics, inflammatory bowel disease, ulcerative colitis, Crohn's disease, Escherichia coli, Lactobacillus and Bifidobacterium. The language was limited to studies published in English. The retrieval results were reviewed by two evaluators. The evaluators were not blinded to the study drug, authors, institutions or journals when reviewing the studies. All of the randomized controlled studies that compared probiotics with standard treatments used for IBD or placebo were collected. Both adult and pediatric studies were included. All IBD patients were diagnosed based on the definite diagnostic standards in all of the included studies. Reviews, case reports, and abstracts and presentations of meetings were excluded.

The risk of bias was evaluated in accordance with the Cochrane Handbook for Systematic Reviews of Interventions, using the following parameters: adequacy of random sequence generation; allocation concealment; blinding of participants, personnel and outcome assessors; incomplete outcome data and selective outcome reporting [43]. The Jadad score was also used to evaluate the quality of each RCT. Briefly, the details of randomization, blinding procedure and information on withdrawals were evaluated. One point was awarded for the specification of each criterion (Table 1). High-quality RCTs which scored three points or more were included in this review [44]. A funnel plot was generated to assess the possibility of publication bias [45].

\section{Data collection and bias assessment}

The interventions used for treatment and control, disease severities, administration procedures, number of enrolled patients and observation intervals were extracted from each study. In the articles associated with remission induction therapy for IBD, the remission or response rates of the probiotic treatment and control groups were extracted, regardless of whether the data were part of the primary or secondary endpoint. Similarly, the relapse rates of the diseases were extracted from the articles associated with maintenance therapy for IBD. An intention-to-treat analysis was chosen for the total number of patients enrolled in each group. A forest plot analysis was used to verify the relative strength of the treatment effects in multiple quantitative scientific studies. The inter-study heterogeneity was tested and quantified using the Cochran Q statistic and the $I^{2}$ statistic, respectively. Funnel plots were used to obtain evidence of publication bias when two or more studies were included.

\section{Statistical analysis}

The relative risk and $95 \%$ confidence interval $(95 \% \mathrm{CI})$ were calculated based on the data. The statistical analysis was performed with the Cochrane Collaboration's Revman 5.0 software program. The inter-study heterogeneity was tested using the Cochran $Q$ test, with the significance level set at $P<0.1$, and was quantified by using the $I^{2}$ statistic. If there was any obvious inter-study heterogeneity $\left(I^{2}>50 \%\right)$, the random effects model was chosen; if not, the fixed effects model was chosen.

\section{Results}

Evaluation of the selected studies

A total of 1004 subjects were retrieved. After screening the titles, abstracts or full text and excluding reviews, case reports, uncontrolled tests and basic research studies, 27 studies were selected. Thereafter, seven studies were excluded because of a low Jadad score $(<3)$ (Table 1$)$. The characteristics of the 20 studies included are shown in Table 2. Of these 20 studies, three were conducted on the response rate to probiotic treatment, four studies examined the remission induction rate and two studies evaluated both the response and remission induction rates of UC patients, five studies focused on the maintenance therapy for UC, two studies on the maintenance therapy for an ileal pouch (Table 3), one study was performed on the remission induction therapy for $\mathrm{CD}$ and four studies examined the effects of probiotics on the maintenance therapy for $\mathrm{CD}$ (Table 4).

\section{The effects of probiotic treatment on induction of remission in $\mathrm{UC}$}

Five studies which investigated the effects of probiotic treatment on the induction of remission described a response rate as an endpoint (Table 2). The VSL\#3 preparation was used as the probiotic treatment in two studies [46, 47]. Bifidobacteria-fermented milk, Bifidobacterium longum/Synergy 1 and Lactobacillus reuteri ATCC 55730 were used as the probiotic treatments in the other three studies [48-50]. Four studies used a placebo as the control intervention [46, 48-50], and the other study used 
Table 1 The risk of bias in the included studies

\begin{tabular}{|c|c|c|c|c|c|c|}
\hline References & $\begin{array}{l}\text { Random sequence } \\
\text { generation }\end{array}$ & $\begin{array}{l}\text { Allocation } \\
\text { concealment }\end{array}$ & $\begin{array}{l}\text { Blind participants, personnel } \\
\text { and outcome assessors } \\
\text { of outcome }\end{array}$ & Incomplete outcome data & $\begin{array}{l}\text { Selective } \\
\text { reporting }\end{array}$ & $\begin{array}{l}\text { Jadad } \\
\text { score }\end{array}$ \\
\hline$[55]$ & Unclear & Unclear & High & High & High & 4 \\
\hline$[51]$ & Unclear & Unclear & Low & High & High & 3 \\
\hline$[62]$ & High & High & High & High & High & 5 \\
\hline$[59]$ & High & High & High & High & High & 5 \\
\hline$[60]$ & High & High & High & High & High & 5 \\
\hline$[48]$ & Unclear & Unclear & High & Low & High & 3 \\
\hline$[52]$ & Unclear & Unclear & Low & High & High & 3 \\
\hline$[56]$ & Unclear & Unclear & High & High & High & 4 \\
\hline$[50]$ & High & High & High & High & High & 5 \\
\hline$[63]$ & Unclear & Unclear & High & High & High & 5 \\
\hline$[57]$ & Unclear & Unclear & Low & High & High & 3 \\
\hline$[64]$ & High & High & High & High & High & 5 \\
\hline [65] & High & High & High & High & High & 5 \\
\hline [53] & High & High & High & High & High & 5 \\
\hline [46] & High & High & High & High & High & 5 \\
\hline [54] & High & High & High & High & High & 5 \\
\hline [47] & High & High & High & High & High & 5 \\
\hline [61] & High & High & High & High & High & 5 \\
\hline [58] & High & High & Low & High & High & 4 \\
\hline [49] & High & High & High & High & High & 5 \\
\hline
\end{tabular}

balsalazide with the probiotic treatment or placebo [47]. The treatments were orally administered in four studies [46-48, 50] and anally in one study [49]. The observation intervals were 12 weeks in two studies $[46,48], 8$ weeks in two studies [47, 49] and 4 weeks in one study [50].

Three studies revealed a significant improvement in the response rate $[46,47,49]$. Of these three studies, one study proposed that the probiotic effect was exerted in a concentration-dependent manner [46]. The other two studies $[48,50]$ showed no significant improvements, but both had investigated small sample sizes (Table 3). Because the inter-study heterogeneity of these five studies was very low $\left(P=0.43, I^{2}=0 \%\right)$, a fixed-effects model was applied to analyze the effects of the probiotic. These five reports included a total of 362 patients. Of these 362 patients, probiotic treatments were used in 184 patients, and 178 patients were treated with a placebo with or without conventional therapies. The total response rate of the probiotic treatment group was $51.1 \%(94 / 184)$, while that in the placebo group was $28.7 \%(51 / 178)$. The risk ratio (RR) of all patients was 1.81 , and the $95 \%$ confidence interval (CI) was 1.40-2.35 (Fig. 1a). The analysis therefore showed that the probiotic treatments were useful for decreasing the severity of the active UC in comparison to the placebo. Funnel plots of these studies showed a symmetrical distribution, thus suggesting low publication bias (Fig. 2a).
Six studies which investigated the effects of probiotic treatment on the induction of remission described the remission induction rate as an endpoint (Table 2). One study was excluded because all patients received steroid therapy [51]. In the remaining five studies, VSL\#3 was used as the probiotic treatment in two studies [52, 53]. Bifidobacteriafermented milk, E. coli strain Nissle 1917 and L. reuteri ATCC 55730 were used as the probiotic treatments in the other three studies $[48,49,54]$. Three studies used a placebo as the control intervention [48, 49, 54] and the other two studies used conventional therapies with the probiotic treatment or placebo $[52,53]$. The medications were orally administered in three studies [48, 52, 53] and anally administered in two studies [49, 54]. The observation interval was 12 weeks in one study [48], 8 weeks in three studies [49, 52, 54] and 4 weeks in one study [53].

One study [53] revealed a significant improvement in the remission induction rate, while the other four studies [48, 49, 52, 54] individually showed no significant improvements (Table 3). Because the inter-study heterogeneity of these five studies was high $(P=0.048$, $I^{2}=58.4 \%$ ), a random-effects model was applied for the analysis of the effects of the probiotic on improving the remission induction rate. These reports included a total of 230 patients. Among these patients, probiotic treatments were used in 140 patients, and 90 patients were treated with 


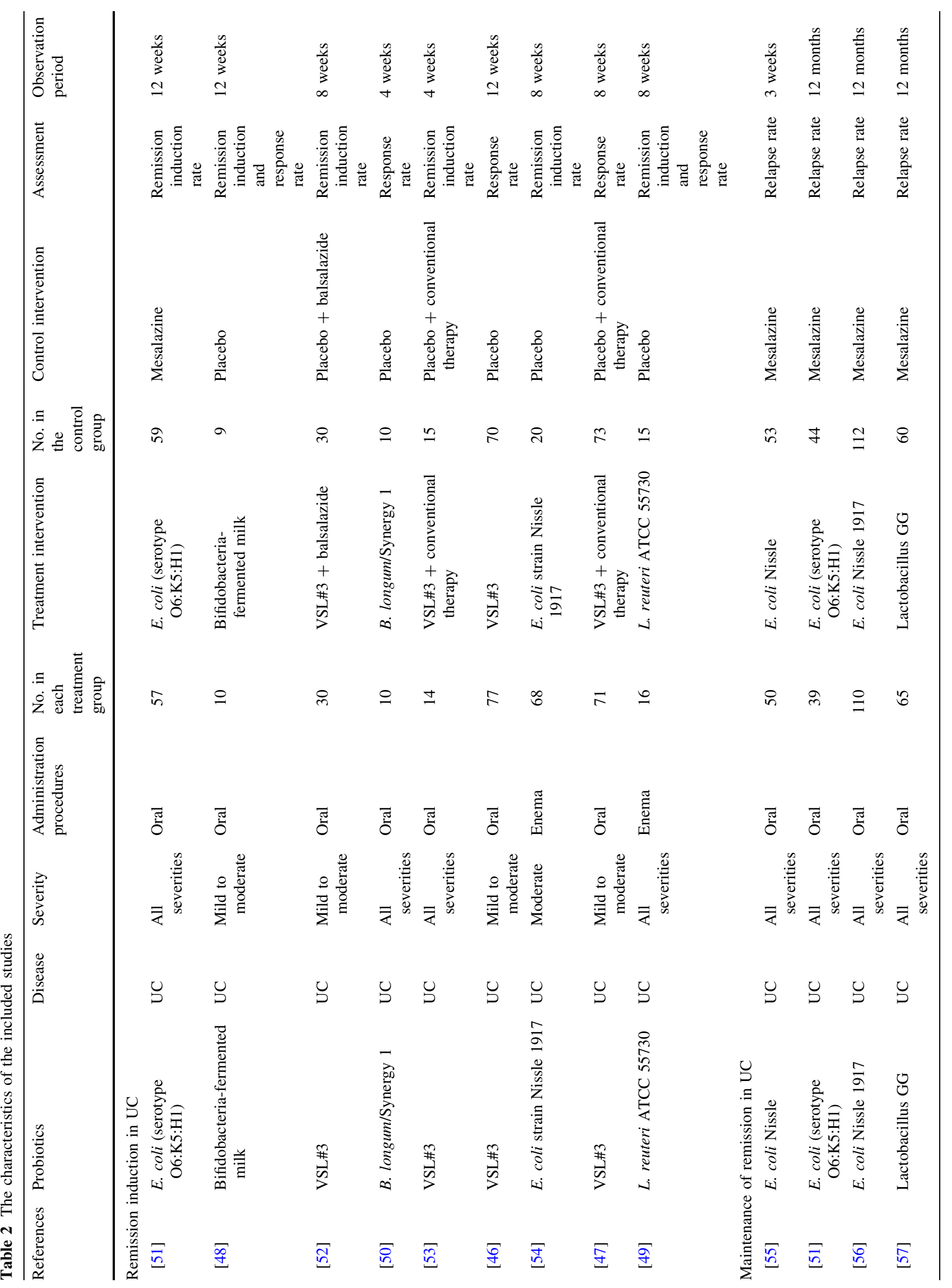




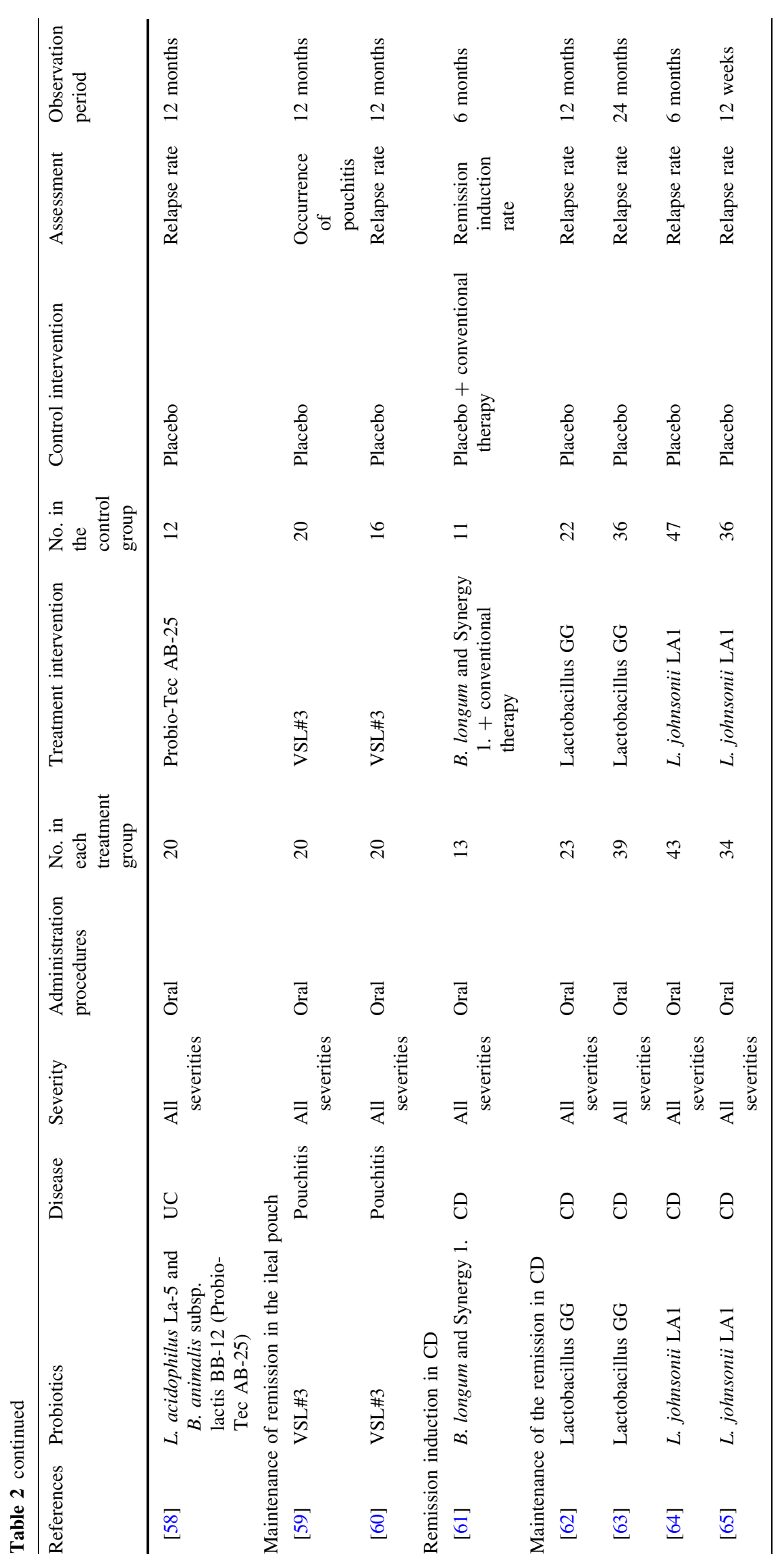


Table 3 Data included in the studies of treatment of UC

\begin{tabular}{|c|c|c|c|c|c|c|c|}
\hline References & $\begin{array}{l}\text { No. of treated } \\
\text { subjects }\end{array}$ & & $\begin{array}{l}\text { of responders in } \\
\text { reated cases }\end{array}$ & $\begin{array}{l}\text { No. of control } \\
\text { subjects }\end{array}$ & $\begin{array}{l}\text { No. of responders } \\
\text { in control cases }\end{array}$ & $\mathrm{RR}$ & $95 \% \mathrm{CI}$ \\
\hline \multicolumn{8}{|c|}{ A. Remission induction in UC (Response rates) } \\
\hline Kato et al. [48] & 10 & & & 10 & 4 & 1.75 & $0.74-4.14$ \\
\hline Furrie et al. [50] & 10 & & & 10 & 3 & 1.67 & $0.54-5.17$ \\
\hline Sood et al. [46] & 77 & & & 70 & 7 & 3.25 & $1.50-7.03$ \\
\hline Tursi et al. [47] & 71 & & & 73 & 29 & 1.45 & $1.03-2.05$ \\
\hline Oliva et al. [49] & 16 & & & 15 & 8 & 1.88 & $1.17-3.01$ \\
\hline References & $\begin{array}{l}\text { No. of treated } \\
\text { subjects }\end{array}$ & & $\begin{array}{l}\text { reated cases that } \\
\text { d remission }\end{array}$ & $\begin{array}{l}\text { No. of control } \\
\text { subjects }\end{array}$ & $\begin{array}{l}\text { No. of control cases that } \\
\text { achieved remission }\end{array}$ & $\mathrm{RR}$ & $95 \% \mathrm{CI}$ \\
\hline \multicolumn{8}{|c|}{ B. Remission induction in UC (Remission rates) } \\
\hline Kato et al. [48] & 10 & 4 & & 10 & 3 & 1.33 & $0.40-4.49$ \\
\hline Tursi et al. [52] & 30 & 24 & & 30 & 21 & 1.14 & $0.85-1.53$ \\
\hline Miele et al. [53] & 14 & 13 & & 15 & 4 & 3.48 & $1.49-8.16$ \\
\hline Matthes et al. [54] & 70 & 29 & & 20 & 7 & 1.18 & $0.61-2.29$ \\
\hline Oliva et al. [49] & 16 & 5 & & 15 & 0 & 10.33 & $0.62-171.78$ \\
\hline References & $\begin{array}{l}\text { No. of tr } \\
\text { subjects }\end{array}$ & & $\begin{array}{l}\text { No. of relapses } \\
\text { in treated cases }\end{array}$ & $\begin{array}{l}\text { No. of control } \\
\text { subjects }\end{array}$ & $\begin{array}{l}\text { No. of relapses } \\
\text { in control cases }\end{array}$ & $\mathrm{RR}$ & $95 \%$ CI \\
\hline \multicolumn{8}{|c|}{ C. Maintenance of remission in UC } \\
\hline Kruis et al. [55] & 50 & & 8 & 53 & 6 & 1.43 & $0.48-4.24$ \\
\hline Rembacken et al. [51] & 39 & & 26 & 44 & 32 & 0.92 & $0.69-1.22$ \\
\hline Kruis et al. [56] & 162 & & 40 & 165 & 38 & 1.07 & $0.75-1.53$ \\
\hline Zocco et al. [57] & 65 & & 10 & 60 & 12 & 0.77 & $0.36-1.65$ \\
\hline Wildt et al. [58] & 20 & & 15 & 12 & 11 & 0.82 & $0.60-1.11$ \\
\hline References & $\begin{array}{l}\text { No. of trea } \\
\text { subjects }\end{array}$ & & $\begin{array}{l}\text { No. of relapses } \\
\text { in treated cases }\end{array}$ & $\begin{array}{l}\text { No. of control } \\
\text { subjects }\end{array}$ & $\begin{array}{l}\text { No. of relapses } \\
\text { in control cases }\end{array}$ & $\mathrm{RR}$ & $95 \%$ CI \\
\hline \multicolumn{8}{|c|}{ D. Maintenance of remission in the ileal pouch } \\
\hline Gionchetti et al. [59] & 20 & & 2 & 20 & 8 & 0.25 & $0.06-1.03$ \\
\hline Mimura et al. [60] & 20 & & 3 & 16 & 15 & 0.16 & $0.06-0.46$ \\
\hline
\end{tabular}

No. number, $R R$ relative risk, $95 \% C I 95 \%$ confidence interval

a placebo with or without conventional therapies. The total remission induction rate of the probiotics therapy group was $53.6 \%(75 / 140)$ and that of the non-probiotics therapy group was $38.9 \%(35 / 90)$. The RR in all patients was 1.56 , and the $95 \%$ CI was $0.95-2.59$ (Fig. 1b). Therefore, probiotic treatment tended to be, but was not significantly, effective for improving the remission induction rate. Funnel plots of these studies showed a symmetrical distribution, suggesting low publication bias (Fig. 2b).

\section{The effects of probiotic treatment on maintenance of remission of $\mathrm{UC}$}

Five studies investigated the effects of probiotic treatment on the maintenance of remission (Table 2). Escherichia coli Nissle was used as probiotic treatment in two studies [55,
56]. Escherichia coli (serotype O6:K5:H1), Lactobacillus GG and Probio-Tec AB-25 (Lactobacillus acidophilus La-5 and Bifidobacterium animalis subsp. lactis BB-1) were used as probiotic treatments in the other three studies [51, 57, 58]. Medications were orally administered in all studies. The observation intervals were 12 months in four studies [51, 56-58] and 3 weeks in one study [55]. Mesalazine was used as a control intervention in four studies. One study used placebo as a control intervention, and showed no significant effect of probiotic treatment on the prevention of relapse in UC. The four that used mesalazine as a control intervention were included in a subsequent analysis. Because the inter-study heterogeneity of the four studies was very low $\left(P=0.7075, I^{2}=0 \%\right)$, a fixed-effects model was applied for the analysis of the probiotic effects. These reports included a total of 638 patients. Among these 638 patients, probiotic treatments were used in 316 patients, 


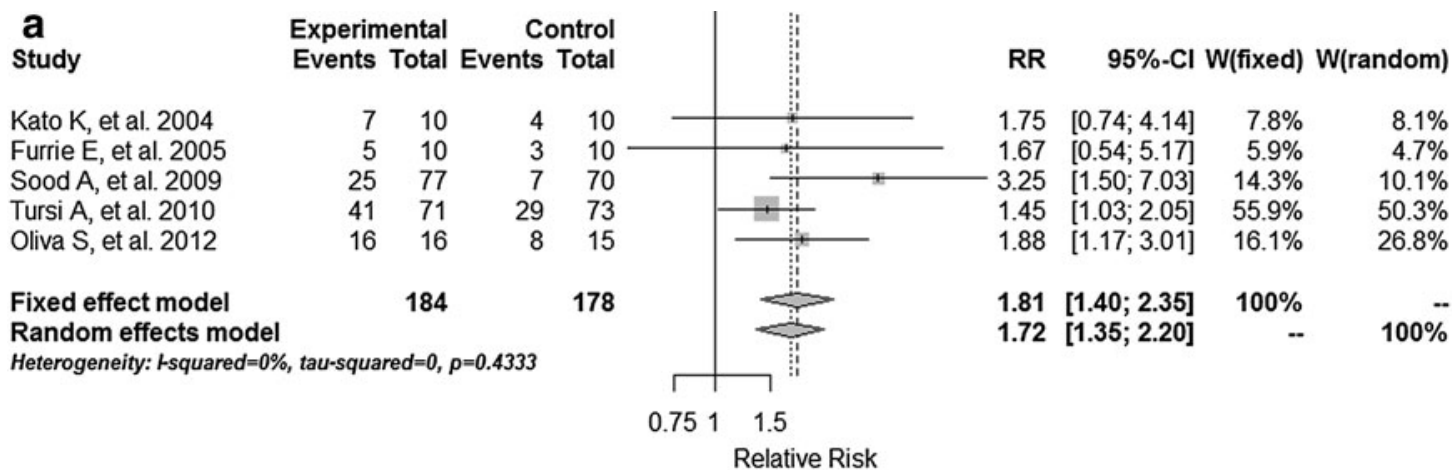

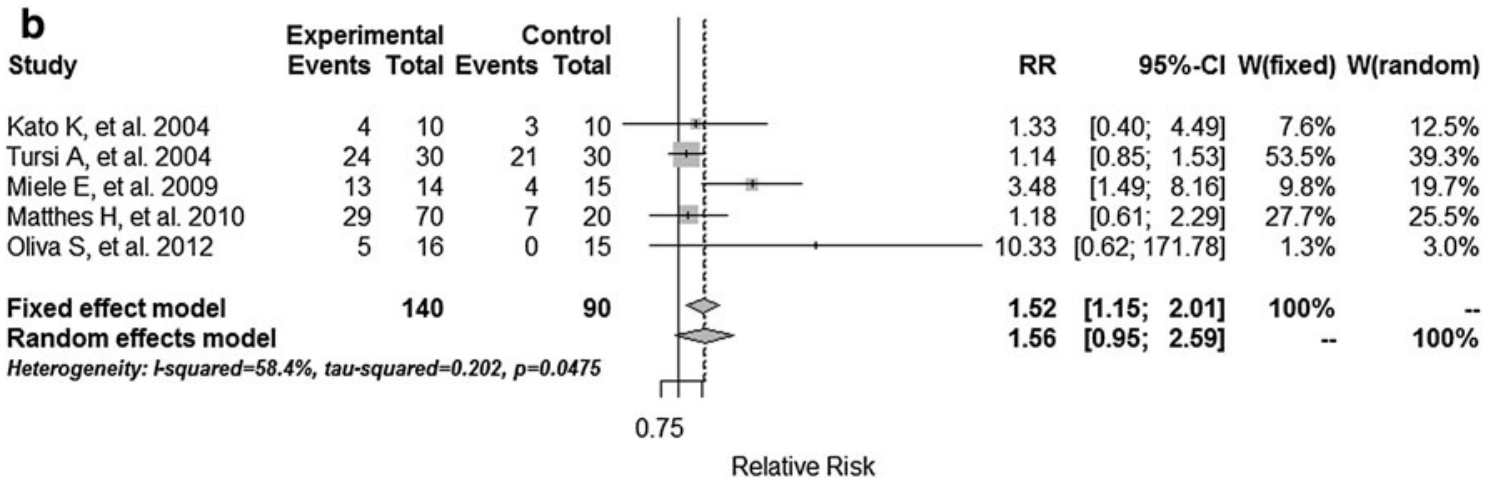

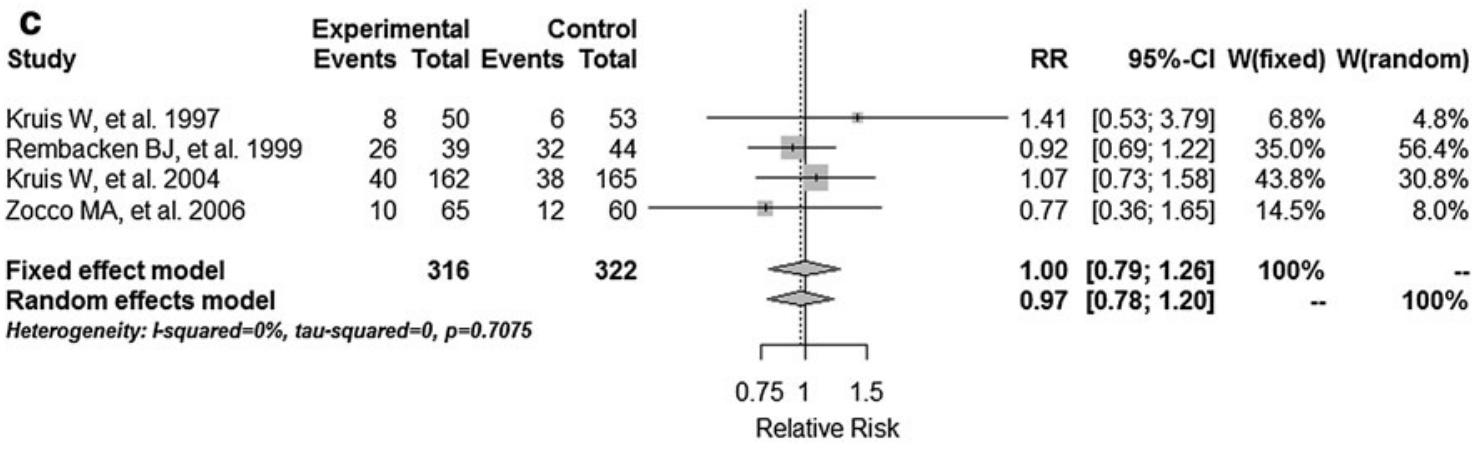

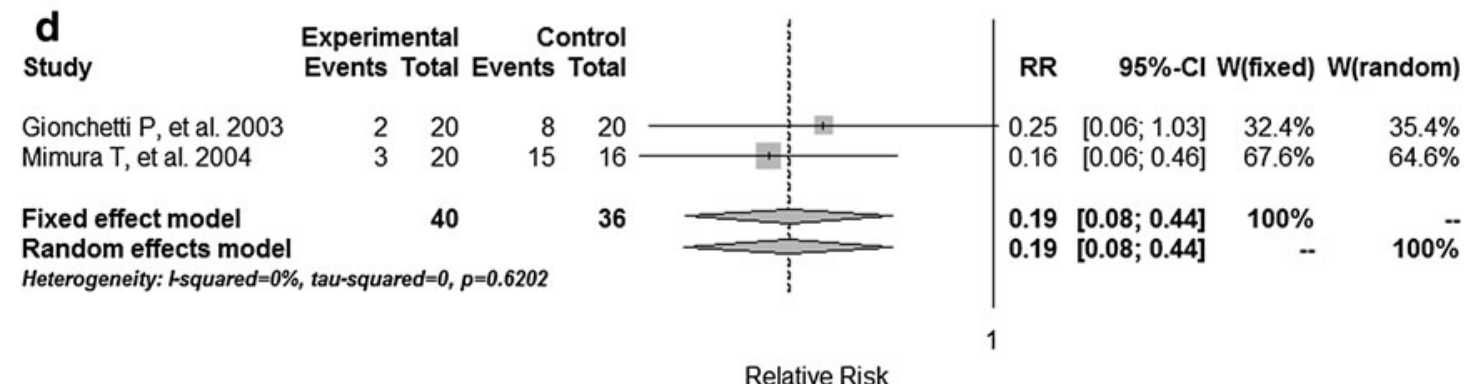

Fig. 1 Forest plots of the response, remission induction and relapse rates of the probiotic group versus the control group in UC. Forest plots of the fixed-effects comparison of probiotics vs. placebo for the response rate (a), remission induction rate (b), relapse rate during the remission stage of $\mathrm{UC}$ (c) and remission in the ileal pouch in postoperative UC patients (d) are shown. For each comparison, the results of tests for heterogeneity are shown, in addition to the $Z$ statistic and associated $P$ value for the strength of the observed effect 

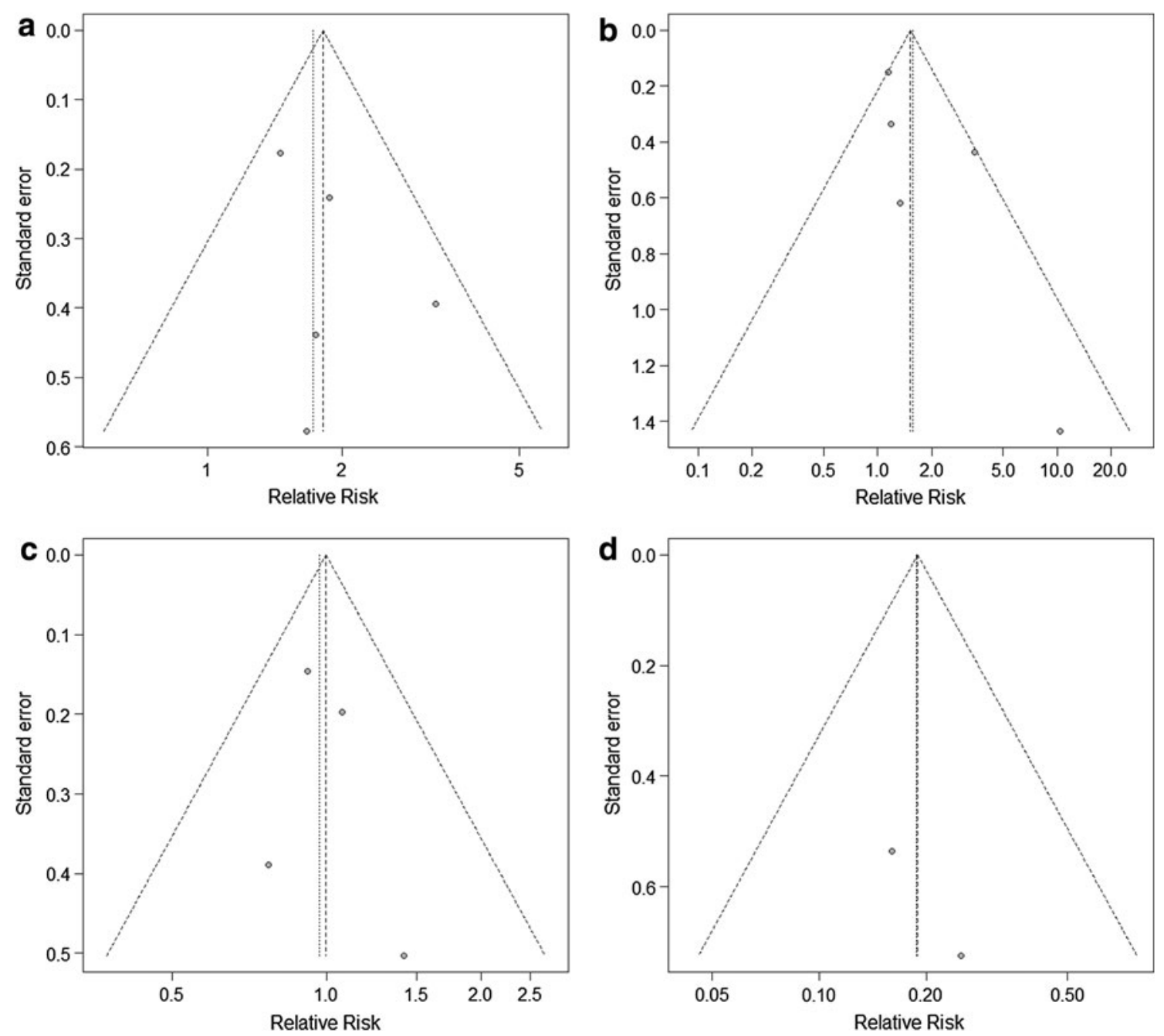

Fig. 2 The results of the inverted funnel plot analysis of the response, remission induction and relapse rates in UC patients. The inverted funnel plot analysis of the relative response rate (a), remission rate

(b), and relapse rate in the remission stage of $\mathrm{UC}(\mathbf{c})$, and remission in the ileal pouch in postoperative UC patients (d) between the probiotics group and placebo group are shown

and 322 patients were treated with standard therapy (mesalazine). The total relapse rate of the probiotics therapy group was $25.0 \%$ (84/336) and that in the mesalazine group was $26.3 \%$ (88/334). The RR in all patients was 1.00 , and the $95 \%$ CI was $0.79-1.26$ (Fig. 1c). Therefore, probiotic treatment could prevent the relapse of UC as effectively as the administration of mesalazine. Funnel plots of these studies showed a symmetrical distribution, suggesting low publication bias (Fig. 2c).

\section{The effects of probiotic treatment on maintenance of remission in the ileal pouch}

Two studies investigated the effects of probiotic treatment on the maintenance of remission in the ileal pouch $[59,60]$ (Table 2). Oral administration of VSL\#3 was used as a

probiotic treatment, a placebo was used as a control intervention and the observation interval was 12 months in both of these studies. Because the inter-study heterogeneity of these two studies was very low $\left(P=0.62, I^{2}=0 \%\right)$, a fixed-effects model was applied for the analysis of the probiotic effects. These reports included a total of 76 patients. Among the 76 patients, probiotic treatments were used in 40 patients, and 36 patients were treated by standard therapy (mesalazine). The total relapse rate of the probiotics therapy group was $26.5 \%(5 / 40)$ and that of the non-probiotics therapy group was $29.6 \%$ (23/36). The RR in all patients was 0.19 , and the $95 \%$ CI was $0.08-0.44$ (Fig. 1d). Therefore, probiotic treatment helps to prevent pouchitis in postoperative UC. The funnel plot of these studies showed a symmetrical distribution; however, it is difficult to determine the grade of the publication bias because only two studies were analyzed (Fig. 2d). 


\section{The effects of probiotic treatment on induction of remission of CD}

Only one study investigated the effects of probiotic treatment on the induction of remission in CD [61] (Table 2). Patients were administered conventional $\mathrm{CD}$ therapies with B. longum and Synergy 1 or placebo. The study showed that $62 \%$ of patients in the probiotic treatment group (8 of 13) and $45 \%$ of those in the placebo group (5 of 11) achieved remission. The RR was 1.35 , and the $95 \%$ CI was $0.62-1.94$, indicating that the additional administration of B. longum and Synergy 1 did not significantly improve the remission induction rate in $\mathrm{CD}$ patients.

\section{The effects of probiotic treatment on maintenance of remission in $C D$ patients}

Four studies investigated the effects of probiotic treatment on the maintenance of remission in CD patients [62-65] (Table 2). Two studies used Lactobacillus GG as a probiotic treatment $[62,63]$ and the other two used Lactobacillus johnsonii LA1 $[64,65]$. The medication was orally administered and a placebo was used as a control intervention in all four studies. The observation intervals were 3 months [65], 6 months [64], 12 months [62] and 24 months [63] in these studies. Because the inter-study heterogeneity of these four studies was very low $(P=0.245$, $I^{2}=27.9 \%$ ), a fixed-effects model was applied for the analysis of the probiotic effects. These reports included a total of 180 patients. Among the 180 patients, probiotic treatments were used in 139 patients, and 141 patients were treated with a placebo. The total relapse rate of the probiotics therapy group was $26.5 \%(35 / 139)$ and that of the non-probiotics therapy group was $29.6 \%$ (29/141). The RR in all patients was 1.18 , and the $95 \%$ CI was $0.81-1.70$ (Fig. 3a). Therefore, probiotic treatment did not contribute to preventing the relapse in postoperative $\mathrm{CD}$ patients. Funnel plots of these studies did not show a symmetrical distribution, and thus a publication bias may have been present (Fig. 3b).

\section{Discussion}

This systematic review assessed the effects of probiotics on the treatment of UC and CD using a meta-analysis. In UC, the analysis revealed that probiotic treatment was useful for relieving the disease activity, increasing the remission induction rate, and preventing the relapse of disease in UC patients as effectively as the administration of mesalazine, and could decrease the development of pouchitis in postoperative UC patients. These results indicate that probiotic treatment is useful in UC in both the active and remission phases.

The present review identified nine RCTs which investigated the effects of probiotics on the induction of remission. Of the nine studies, five investigated the response rate to probiotic treatment in UC. A forest plot analysis, which is used to verify the relative strength of treatment effects in multiple quantitative scientific studies, found that there was significant efficacy of probiotic treatment for improving the activity of UC (RR 1.18, $95 \%$ CI 1.40-2.35). Furthermore, in five studies which examined the remission induction rate, probiotic treatment tended to improve the remission induction rate (RR 1.56, $95 \%$ CI $0.95-2.59$ ). The analysis in this review suggests that probiotic treatments provide a sufficient benefit for the induction of remission in UC. In contrast, Mallon et al. [66] showed in their systematic review of four RCTs published from 1999 to 2005 that probiotic treatment was not useful as a remission induction therapy in UC. However, most of the studies included in their review were small in size [48, 50-52], and thus may have lacked the power to detect a statistically significant difference. Compared with their review, the present systematic review included a much larger number of patients, because five more studies published after 2005 were identified [46, 47, 49, 53, 54], and we verified the efficacy of probiotic treatments in inducing remission in UC.

The present review also identified five RCTs that investigated the effects of probiotics on the maintenance of UC [51, 55-58]. One study used a placebo as a control intervention [58], and four studies compared the effects of probiotic treatment with mesalazine [51, 55-57]. A forest plot analysis of these four studies showed no difference between the effects of probiotic treatments and mesalazine administration on the maintenance of remission in UC (RR $1.00,95 \%$ CI $0.79-1.26$ ), validating that probiotic treatment is useful for maintaining remission in patients with quiescent UC. In addition, the present review also identified two studies that investigated the effects of probiotic treatment on the maintenance of remission in the ileal pouch of postoperative UC patients, and revealed a significant benefit of probiotic treatment in the prevention of pouchitis (RR $0.19,95 \%$ CI $0.08-0.44$ ). Naidoo et al. previously reviewed four studies and showed that there was insufficient evidence to draw conclusions about the efficacy of probiotics for maintenance of remission in UC [66]. Their review included studies that used either mesalazine or placebo as a control intervention. This variation between our study and theirs was thought to be the cause of their failure to draw a conclusion. The present review thus excluded a study that used a placebo as a control intervention [58] and analyzed the other four studies [51, 5557], and we were able to verify the efficacy of probiotic 

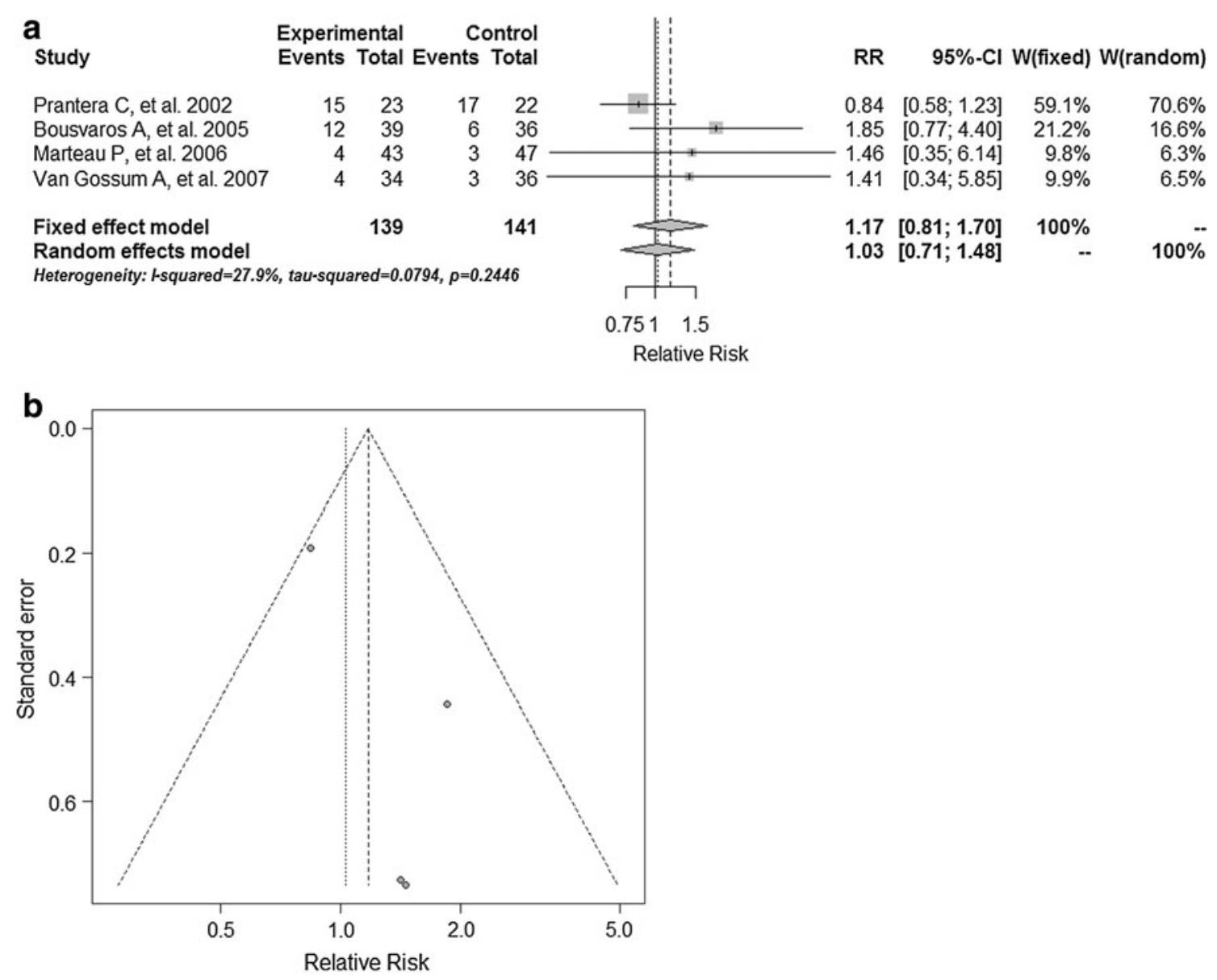

Fig. 3 Forest plots and the results of the inverted funnel plot analysis of the relative relapse rates in CD. Forest plots of the fixed-effects comparison of probiotics vs. placebo for the response rate (a), and the

treatments for the maintenance of remission in UC patients. Sang et al. [67] also suggested in their systematic review that probiotic treatments were more effective than placebo for maintaining remission in ulcerative colitis, despite the fact that low-quality studies were included. Consequently, such RCTs suggest that there is a significant effect of probiotic treatment on the induction and maintenance of remission in UC, despite variations in the design and treatment interventions among the studies (Table 2).

While the results of the present review and other studies suggested a beneficial effect of probiotic treatments on the induction and maintenance of remission in UC, there are some limitations to these studies, including variations in the inclusion and exclusion criteria, the treatment and control interventions, schedules and concentrations of the probiotics, observation intervals, procedures used to assess the disease activity, concomitant medications, the ethnicity of the patients and the lifestyles of the enrolled patients. Therefore, the optimal probiotic treatment for UC patients in the active and quiescent phases needs to be investigated in further RCTs. results of the inverted funnel plot analysis of the relative relapse rate in the remission stage in $\mathrm{CD}$ patients (b) are shown

In $\mathrm{CD}$ patients, one RCT which investigated the effects of probiotics on the induction of remission and four RCTs which investigated the effects on the maintenance of remission in CD patients were identified. All of the studies showed no significant effects on either the induction or maintenance of remission in $\mathrm{CD}$. The forest plot verified no beneficial effect of the probiotic treatments on the maintenance of remission in $\mathrm{CD}$. Rolfe et al. [68] reviewed seven studies, including abstracts, of maintenance therapy in CD by Lactobacillus administration. The meta-analysis indicated that Lactobacillus administration was not effective for the maintenance of remission in $\mathrm{CD}$ patients. Shen et al. [69] also reviewed six controlled studies, including original articles, as well as abstracts and meeting reports, of maintenance therapy in CD by Lactobacillus administration and obtained the same conclusion. Another two metaanalyses investigated the effects of probiotics on maintenance therapy for postoperative $\mathrm{CD}$, and concluded that probiotics were not superior to placebo for any outcome measured [70, 71]. Taken together, these studies indicate that probiotic treatments appear to be insufficient to induce 
an effect on either the induction or maintenance of remission in $\mathrm{CD}$.

In summary, the present study identified 20 high-quality RCTs which investigated the effects of probiotics on the induction or maintenance of remission in IBD. From the results of the validation of these RCTs, probiotic treatment is a practical option for UC patients as both remission induction and maintenance therapy, but such treatment is not effective in $\mathrm{CD}$ patients. Because there were many variations in the conditions among the studies, future studies on the value of probiotic treatment in IBD should consider the effects of different probiotics and different regimens, together with the specific patient populations which are most likely to benefit from probiotic treatment.

Disclosures Conflict of Interest: The authors declare that they have no conflict of interest.

Human/Animal Rights: All procedures followed were in accordance with the ethical standards of the responsible committee on human experimentation (institutional and national) and with the Helsinki Declaration of 1975, as revised in 2008(5).

Informed Consent: Informed consent was obtained from all patients for being included in the study.

\section{References}

1. Qin J, Li R, Raes J, et al. A human gut microbial gene catalogue established by metagenomic sequencing. Nature. 2010;464:59-65.

2. Devkota S, Wang Y, Musch MW, et al. Dietary-fat-induced taurocholic acid promotes pathobiont expansion and colitis in Il10-/- mice. Nature. 2012;487:104-8.

3. Turnbaugh PJ, Ley RE, Hamady M, et al. The human microbiome project. Nature. 2007;449:804-10.

4. McFall-Ngai M. Adaptive immunity: care for the community. Nature. 2007;445:153.

5. Pennisi E. Metagenomics. Massive microbial sequence project proposed. Science. 2007;315:1781.

6. Organization WH. Health and nutritional properties of probiotics in food including powder milk with live lactic acid bacteria. http://www.who.int/foodsafety/publications/fs_management/en/ probiotics.pdf (2001).

7. Fuller R. Probiotics in man and animals. J Appl Bacteriol. 1989;66:365-78.

8. Metchnikoff E. The prolongation of life: optimistic studies. New York: Springer; 2004.

9. Cotter PD, Hill C, Ross RP. Bacteriocins: developing innate immunity for food. Nat Rev Microbiol. 2005;3:777-88.

10. Servin AL. Antagonistic activities of lactobacilli and bifidobacteria against microbial pathogens. FEMS Microbiol Rev. 2004;28:405-40.

11. Lawton EM, Ross RP, Hill C, et al. Two-peptide lantibiotics: a medical perspective. Mini Rev Med Chem. 2007;7:1236-47.

12. Morgan SM, O'Connor PM, Cotter PD, et al. Sequential actions of the two component peptides of the lantibiotic lacticin 3147 explain its antimicrobial activity at nanomolar concentrations. Antimicrob Agents Chemother. 2005;49:2606-11.
13. Chaillou S, Champomier-Verges MC, Cornet M, et al. The complete genome sequence of the meat-borne lactic acid bacterium Lactobacillus sakei 23K. Nat Biotechnol. 2005;23:1527-33.

14. Altermann E, Russell WM, Azcarate-Peril MA, et al. Complete genome sequence of the probiotic lactic acid bacterium Lactobacillus acidophilus NCFM. Proc Natl Acad Sci USA. 2005;102:3906-12.

15. Pridmore RD, Berger B, Desiere F, et al. The genome sequence of the probiotic intestinal bacterium Lactobacillus johnsonii NCC 533. Proc Natl Acad Sci USA. 2004;101:2512-7.

16. Makras L, Triantafyllou V, Fayol-Messaoudi D, et al. Kinetic analysis of the antibacterial activity of probiotic lactobacilli towards Salmonella enterica serovar Typhimurium reveals a role for lactic acid and other inhibitory compounds. Res Microbiol. 2006;157:241-7.

17. De Keersmaecker SC, Verhoeven TL, Desair J, et al. Strong antimicrobial activity of Lactobacillus rhamnosus GG against Salmonella typhimurium is due to accumulation of lactic acid. FEMS Microbiol Lett. 2006;259:89-96.

18. Zyrek AA, Cichon C, Helms S, et al. Molecular mechanisms underlying the probiotic effects of Escherichia coli Nissle 1917 involve ZO-2 and PKCzeta redistribution resulting in tight junction and epithelial barrier repair. Cell Microbiol. 2007;9:804-16.

19. Sheth P, Delos Santos N, Seth A, et al. Lipopolysaccharide disrupts tight junctions in cholangiocyte monolayers by a c-Src-, TLR4-, and LBP-dependent mechanism. Am J Physiol Gastrointest Liver Physiol. 2007;293:G308-18.

20. Parassol N, Freitas M, Thoreux K, et al. Lactobacillus casei DN114001 inhibits the increase in paracellular permeability of enteropathogenic Escherichia coli-infected T84 cells. Res Microbiol. 2005;156:256-62.

21. Otte JM, Podolsky DK. Functional modulation of enterocytes by Gram-positive and Gram-negative microorganisms. Am J Physiol Gastrointest Liver Physiol. 2004;286:G613-26.

22. Resta-Lenert S, Barrett KE. Probiotics and commensals reverse TNF-alpha- and IFN-gamma-induced dysfunction in human intestinal epithelial cells. Gastroenterology. 2006;130:731-46.

23. Fujiya M, Musch MW, Nakagawa Y, et al. The Bacillus subtilis quorum-sensing molecule CSF contributes to intestinal homeostasis via OCTN2, a host cell membrane transporter. Cell Host Microbe. 2007;1:299-308.

24. Segawa S, Fujiya M, Konishi H, et al. Probiotic-derived polyphosphate enhances the epithelial barrier function and maintains intestinal homeostasis through integrin-p38 MAPK pathway. PLoS One. 2011;6:e23278.

25. Bakker-Zierikzee AM, Tol EA, Kroes H, et al. Faecal SIgA secretion in infants fed on pre- or probiotic infant formula. Pediatr Allergy Immunol. 2006;17:134-40.

26. Wehkamp J, Harder J, Wehkamp K, et al. NF-kappaB- and AP-1mediated induction of human beta defensin-2 in intestinal epithelial cells by Escherichia coli Nissle 1917: a novel effect of a probiotic bacterium. Infect Immun. 2004;72:5750-8.

27. Schlee M, Harder J, Koten B, et al. Probiotic lactobacilli and VSL\#3 induce enterocyte beta-defensin 2. Clin Exp Immunol. 2008;151:528-35.

28. Pena JA, Versalovic J. Lactobacillus rhamnosus GG decreases TNF-alpha production in lipopolysaccharide-activated murine macrophages by a contact-independent mechanism. Cell Microbiol. 2003;5:277-85.

29. Sturm A, Rilling K, Baumgart DC, et al. Escherichia coli Nissle 1917 distinctively modulates T-cell cycling and expansion via toll-like receptor 2 signaling. Infect Immun. 2005;73: 1452-65.

30. Kim SO, Sheikh HI, Ha SD, et al. G-CSF-mediated inhibition of JNK is a key mechanism for Lactobacillus rhamnosus-induced 
suppression of TNF production in macrophages. Cell Microbiol. 2006;8:1958-71.

31. Drakes M, Blanchard T, Czinn S. Bacterial probiotic modulation of dendritic cells. Infect Immun. 2004;72:3299-309.

32. Hart AL, Lammers K, Brigidi $\mathrm{P}$, et al. Modulation of human dendritic cell phenotype and function by probiotic bacteria. Gut. 2004;53:1602-9.

33. Smits HH, Engering A, van der Kleij D, et al. Selective probiotic bacteria induce IL-10-producing regulatory $\mathrm{T}$ cells in vitro by modulating dendritic cell function through dendritic cell-specific intercellular adhesion molecule 3-grabbing nonintegrin. J Allergy Clin Immunol. 2005;115:1260-7.

34. Ma D, Forsythe P, Bienenstock J. Live Lactobacillus rhamnosus [corrected] is essential for the inhibitory effect on tumor necrosis factor alpha-induced interleukin-8 expression. Infect Immun. 2004;72:5308-14.

35. O'Hara AM, O'Regan P, Fanning A, et al. Functional modulation of human intestinal epithelial cell responses by Bifidobacterium infantis and Lactobacillus salivarius. Immunology. 2006;118:202-15.

36. Zhang L, Li N, Caicedo R, et al. Alive and dead Lactobacillus rhamnosus GG decrease tumor necrosis factor-alpha-induced interleukin-8 production in Caco-2 cells. J Nutr. 2005;135:1752-6.

37. Petrof EO, Claud EC, Sun J, et al. Bacteria-free solution derived from Lactobacillus plantarum inhibits multiple NF-kappaB pathways and inhibits proteasome function. Inflamm Bowel Dis. 2009;15:1537-47.

38. Kelly D, Campbell JI, King TP, et al. Commensal anaerobic gut bacteria attenuate inflammation by regulating nuclear-cytoplasmic shuttling of PPAR-gamma and RelA. Nat Immunol. 2004;5:104-12.

39. Are A, Aronsson L, Wang S, et al. Enterococcus faecalis from newborn babies regulate endogenous PPARgamma activity and IL-10 levels in colonic epithelial cells. Proc Natl Acad Sci USA. 2008;105:1943-8.

40. Nenci A, Becker C, Wullaert A, et al. Epithelial NEMO links innate immunity to chronic intestinal inflammation. Nature. 2007;446:557-61.

41. Sartor RB. Therapeutic manipulation of the enteric microflora in inflammatory bowel diseases: antibiotics, probiotics, and prebiotics. Gastroenterology. 2004;126:1620-33.

42. Fujiya MKY. Novel perspectives in probiotic treatment: the efficacy and unveiled mechanisms of the physiological functions. Clin J Gastroenterol. 2010;3:11.

43. Higgins JPT, Green S. Cochrane handbook for systematic reviews of interventions Version 5.1.0: The Cochrane Collaboration, 2011.

44. Moher D, Jadad AR, Nichol G, et al. Assessing the quality of randomized controlled trials: an annotated bibliography of scales and checklists. Control Clin Trials. 1995;16:62-73.

45. Derry S, Loke YK, Aronson JK. Incomplete evidence: the inadequacy of databases in tracing published adverse drug reactions in clinical trials. BMC Med Res Methodol. 2001;1:7.

46. Sood A, Midha V, Makharia GK, et al. The probiotic preparation, VSL\#3 induces remission in patients with mild-to-moderately active ulcerative colitis. Clin Gastroenterol Hepatol. 2009; 7: 1202-9 (1209 e1).

47. Tursi A, Brandimarte G, Papa A, et al. Treatment of relapsing mild-to-moderate ulcerative colitis with the probiotic VSL\#3 as adjunctive to a standard pharmaceutical treatment: a doubleblind, randomized, placebo-controlled study. Am J Gastroenterol. 2010;105:2218-27.

48. Kato K, Mizuno S, Umesaki Y, et al. Randomized placebo-controlled trial assessing the effect of bifidobacteria-fermented milk on active ulcerative colitis. Aliment Pharmacol Ther. 2004;20: 1133-41.
49. Oliva S, Di Nardo G, Ferrari F, et al. Randomized clinical trial: the effectiveness of Lactobacillus reuteri ATCC 55730 rectal enema in children with active distal ulcerative colitis. Aliment Pharmacol Ther. 2012;35:327-34.

50. Furrie E, Macfarlane S, Kennedy A, et al. Synbiotic therapy (Bifidobacterium longum/Synergy 1) initiates resolution of inflammation in patients with active ulcerative colitis: a randomized controlled pilot trial. Gut. 2005;54:242-9.

51. Rembacken BJ, Snelling AM, Hawkey PM, et al. Non-pathogenic Escherichia coli versus mesalazine for the treatment of ulcerative colitis: a randomized trial. Lancet. 1999;354:635-9.

52. Tursi A, Brandimarte G, Giorgetti GM, et al. Low-dose balsalazide plus a high-potency probiotic preparation is more effective than balsalazide alone or mesalazine in the treatment of acute mild-to-moderate ulcerative colitis. Med Sci Monit. 2004;10: PI126-31.

53. Miele E, Pascarella F, Giannetti E, et al. Effect of a probiotic preparation (VSL\#3) on induction and maintenance of remission in children with ulcerative colitis. Am J Gastroenterol. 2009;104: 437-43.

54. Matthes H, Krummenerl $\mathrm{T}$, Giensch $\mathrm{M}$, et al. Clinical trial: probiotic treatment of acute distal ulcerative colitis with rectally administered Escherichia coli Nissle 1917 (EcN). BMC Complement Altern Med. 2010;10:13.

55. Kruis W, Schutz E, Fric P, et al. Double-blind comparison of an oral Escherichia coli preparation and mesalazine in maintaining remission of ulcerative colitis. Aliment Pharmacol Ther. 1997;11:853-8.

56. Kruis W, Fric P, Pokrotnieks J, et al. Maintaining remission of ulcerative colitis with the probiotic Escherichia coli Nissle 1917 is as effective as with standard mesalazine. Gut. 2004;53:1617-23.

57. Zocco MA, dal Verme LZ, Cremonini F, et al. Efficacy of Lactobacillus GG in maintaining remission of ulcerative colitis. Aliment Pharmacol Ther. 2006;23:1567-74.

58. Wildt S, Nordgaard I, Hansen U, et al. A randomized doubleblind placebo-controlled trial with Lactobacillus acidophilus La5 and Bifidobacterium animalis subsp. lactis BB-12 for maintenance of remission in ulcerative colitis. J Crohns Colitis. 2011;5:115-21.

59. Gionchetti P, Rizzello F, Helwig U, et al. Prophylaxis of pouchitis onset with probiotic therapy: a double-blind, placebocontrolled trial. Gastroenterology. 2003;124:1202-9.

60. Mimura T, Rizzello F, Helwig U, et al. Once daily high dose probiotic therapy (VSL\#3) for maintaining remission in recurrent or refractory pouchitis. Gut. 2004;53:108-14.

61. Steed H, Macfarlane GT, Blackett KL, et al. Clinical trial: the microbiological and immunological effects of synbiotic consumption - a randomized double-blind placebo-controlled study in active Crohn's disease. Aliment Pharmacol Ther. 2010;32:872-83.

62. Prantera C, Scribano ML, Falasco G, et al. Ineffectiveness of probiotics in preventing recurrence after curative resection for Crohn's disease: a randomized controlled trial with Lactobacillus GG. Gut. 2002;51:405-9.

63. Bousvaros A, Guandalini S, Baldassano RN, et al. A randomized, double-blind trial of Lactobacillus GG versus placebo in addition to standard maintenance therapy for children with Crohn's disease. Inflamm Bowel Dis. 2005;11:833-9.

64. Marteau P, Lemann M, Seksik P, et al. Ineffectiveness of Lactobacillus johnsonii LA1 for prophylaxis of postoperative recurrence in Crohn's disease: a randomised, double blind, placebo controlled GETAID trial. Gut. 2006;55:842-7.

65. Van Gossum A, Dewit O, Louis E, et al. Multicenter randomizedcontrolled clinical trial of probiotics (Lactobacillus johnsonii, LA1) on early endoscopic recurrence of Crohn's disease after ileo-caecal resection. Inflamm Bowel Dis. 2007;13:135-42. 
66. Mallon P, McKay D, Kirk S, et al. Probiotics for induction of remission in ulcerative colitis. Cochrane Database Syst Rev. 2007;4:CD005573.

67. Sang LX, Chang B, Zhang WL, et al. Remission induction and maintenance effect of probiotics on ulcerative colitis: a metaanalysis. World J Gastroenterol. 2010;16:1908-15.

68. Rolfe VE, Fortun PJ, Hawkey CJ, et al. Probiotics for maintenance of remission in Crohn's disease. Cochrane Database Syst Rev. 2006;4:CD004826.
69. Shen J, Ran HZ, Yin MH, et al. Meta-analysis: the effect and adverse events of Lactobacilli versus placebo in maintenance therapy for Crohn disease. Intern Med J. 2009;39:103-9.

70. Doherty G, Bennett G, Patil S, et al. Interventions for prevention of post-operative recurrence of Crohn's disease. Cochrane Database Syst Rev. 2009;4:CD006873.

71. van Loo ES, Dijkstra G, Ploeg RJ, et al. Prevention of postoperative recurrence of Crohn's disease. J Crohns Colitis. 2012;6: 637-46. 